\title{
Age and growth studies of banana prawn, Penaeus merguiensis de Man from Maharashtra waters
}

\author{
*Sushant Mane and Vinay D. Deshmukh \\ Mumbai Research Centre of Central Marine Fisheries Research Institute, $2^{\text {nd }}$ Floor, CIFE Old Campus, \\ Fisheries University Road, Seven Bunglows, Versova, Mumbai 400 061, Maharashtra. \\ *E-mail: sushantmane@yahoo.com
}

\begin{abstract}
Age and growth of Penaeus merguiensis from Maharashtra waters were studied. The estimates obtained by Bhattacharya analysis and Gulland-Holt plot were $\mathrm{L}_{\infty}=203.7 \mathrm{~mm}$ and $\mathrm{K}=2.15 \mathrm{yr}^{-1}$ for males and $\mathrm{L}_{\infty}=254.9 \mathrm{~mm}$ and $\mathrm{K}=1.90 \mathrm{yr}^{-1}$ for females. The maximum size observed for males was $188 \mathrm{~mm}$ and $238 \mathrm{~mm}$ for females. The male and female prawns after one month larval period attain $134.2 \mathrm{~mm}$ and $156.3 \mathrm{~mm}$ length in 6 months and $180.0 \mathrm{~mm}$ and $216.8 \mathrm{~mm}$ in one year respectively.
\end{abstract}

Keywords: Penaeus merguiensis, age and growth, growth parameters, banana prawn

\section{Introduction}

Age and growth studies are necessary for gaining information about age structure and mortality rates of commercially exploited stocks, which enable assessing status of exploitation and subsequent management. Because of moulting, age and growth determination with the help of hard body parts is not possible in prawns (Kurata, 1962) while tagging and recapture often interfere with moulting thus affecting the growth of crustaceans (Garcia and Le Reste, 1981). Hence, length-frequency method have been developed for estimation of growth (Banerjee and George, 1967; Devaraj, 1983, and Pauly and Caddy, 1985).

Penaeus merguiensis occurs throughout the year along the coastal waters of Maharashtra (Deshmukh, 2007). Studies on age and growth of this species were carried out by Kirkegaard et al. (1975), Lucas et al. (1979), Haywood and Staples (1993) and Hoang et al. (2002) from Australia and by Sumiono (1988) from Indonesia. In India, studies were carried out by Achuthankutty and Parulekar (1986) from Goa and Bhadra and Birader (2000) from Mumbai. Growth parameters of closely related species $P$. indicus were estimated by Lalitha Devi (1986) from east cost of India, Agasen and Mundo (1988) and Rao et al.
(1993) and for P. pencillatus by Sultana (2000) from Pakistan.

\section{Material and Methods}

Samples were collected once a week during January 2002 - December 2003 from trawl landings at New Ferry Wharf (NFW) in Mumbai which represented the offshore waters; once a month from trawlers at Harnai landing centre in Ratnagiri district during May 2002 - May 2004 which represented the nearshore waters; and fortnightly from Khamdae village on the banks of Rajpuri creek near Murud during May 2003 - May 2004, representing the inshore estuarine waters. Samples from nearshore and offshore waters could not be collected from June to mid August due to monsoon trawl ban imposed by the state government.

A total of 6,443 males and 7,987 females were measured for the size frequency analysis. Inshore estuarine prawn samples collected from barrier net fishery at Khamde included 1,306 males ranging from 43 to $148 \mathrm{~mm}$ and 1,442 females ranging from 48 to $168 \mathrm{~mm}$. Nearshore samples from Harnai trawling centre included 3,239 males in the size range of 88-188 mm and 3,515 females between 73 and $233 \mathrm{~mm}$. The offshore samples from New Ferry 
Wharf trawling centre included 1,898 males in the size range of $98-183 \mathrm{~mm}$ and 3,030 females between 108 and $238 \mathrm{~mm}$. The maximum observed length for males was $188 \mathrm{~mm}$ and $238 \mathrm{~mm}$ for females.

Total length of prawns was measured separately for sexes from the tip of the rostrum to the end of telson in millimetres. Weight of the samples was recorded using a monopan spring balance. The length measurements were grouped into $5 \mathrm{~mm}$ class intervals for size frequency analysis. The length frequency on the observation day was raised to the total catch of the species for the day and further raised to the monthly estimated catch. Monthly length frequency data were analysed using ELEFAN 1 (Pauly and David, 1981), Powell-Wetherall method (Wetherall et al., 1987). Assuming that Bhattacharya method incorporated in FiSAT software (Gayanilo et al., 1996) was used for separating and connecting the monthwise modes of the two sexes initially and later used as inputs for Gulland and Holt plot (1959), Faben's method (1965) and Appeldoorn's method (1987).

\section{Results and Discussion}

The growth parameters obtained by the various methods for the two sexes are given in the Table 1 . The asymptotic length $\left(\mathrm{L}_{\infty}\right)$ range for males varied from 200-211 mm and the same for females 244$255.26 \mathrm{~mm}$. Despite different methods employed, the variations were not large enough to eliminate estimates of $\mathrm{L}_{\infty}$ and $\mathrm{K}$ by any one method. However, to reduce ambiguity for comparison of the present results and the other studies the estimates obtained by Gulland and Holt plot were considered (Figs. 2a $\& 2 b)$.

The first post-larva of $P$. merguiensis appears after about 10 days from hatching of eggs (Raje and Ranade, 1972) which settles at the bottom to lead benthic life in inshore waters after 5-6 moultings. Therefore, it may not be wrong to presume that the total larval period of the species, until the post-larva settles and follows the von Bertalanffy growth pattern, is about a month. Therefore, using the VBGF growth parameters, 6 month-old male and female prawns would attain total length of $134.2 \mathrm{~mm}$ and $156.3 \mathrm{~mm}$ and $180 \mathrm{~mm}$ and $216.8 \mathrm{~mm}$ in one year respectively (Fig. 1).

Investigations on spawning of $P$. merguiensis revealed peak spawning during post-monsoon period

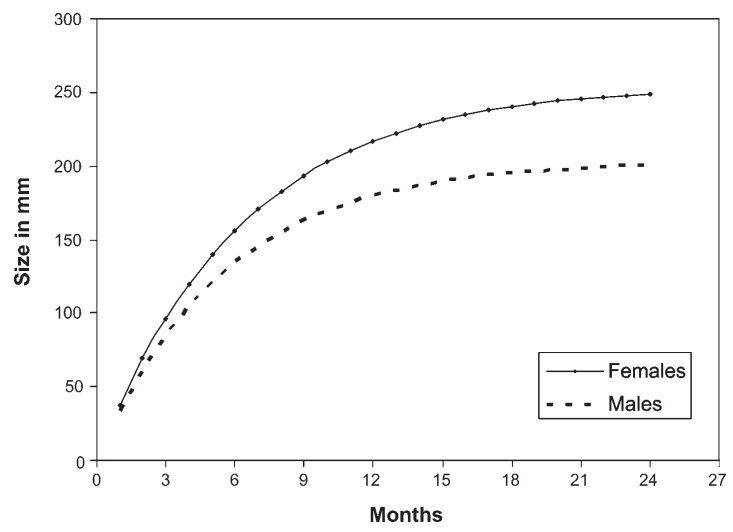

Fig. 1. VBGF curves of males and females

Table 1. Growth parameters of males and females of P. merguiensis obtained by various methods

\begin{tabular}{llll}
\hline \multicolumn{1}{c}{ Method } & Sex & \multicolumn{1}{c}{$\mathrm{L}_{\infty}$} & \multicolumn{1}{c}{$\mathrm{K}$} \\
\hline ELEFAN & $\mathrm{M}$ & 200 & 2.00 \\
& $\mathrm{~F}$ & 252 & 1.9 \\
Powell-Wetherall (1979,1986) & $\mathrm{M}$ & 210.72 & - \\
Bhattacharya method (1967) & $\mathrm{F}$ & 253.97 & - \\
& $\mathrm{M}$ & 204.45 & 1.95 \\
Gulland and Holt (1959) & $\mathrm{F}$ & 251.07 & 1.9 \\
& $\mathrm{M}$ & 203.68 & 2.15 \\
Faben's (1965) & $\mathrm{F}$ & 254.89 & 1.9 \\
& $\mathrm{M}$ & $200.29 \pm 6.80$ & $2.13 \pm 0.31$ \\
Appeldoorn (1987) & $\mathrm{F}$ & $255.26 \pm 5.358$ & $1.89 \pm 0.124$ \\
& $\mathrm{M}$ & $205.90 \pm 9.44$ & $1.87 \pm 0.35$ \\
& $\mathrm{~F}$ & $261.72 \pm 14.09$ & $1.93 \pm 0.25$ \\
\hline
\end{tabular}




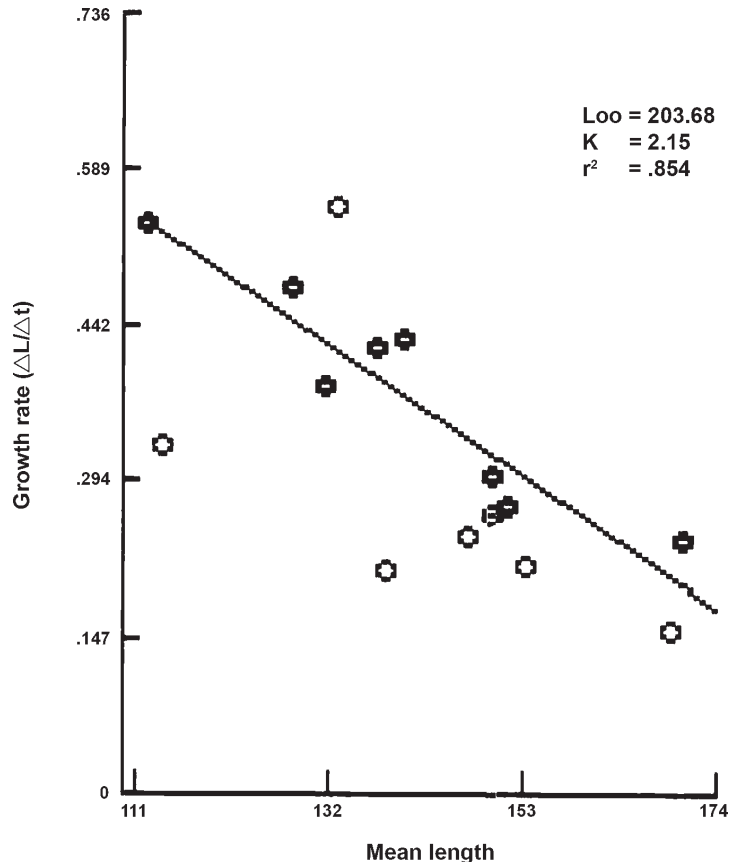

Fig. 2a. Growth curve obtained by Gulland and Holt plot in males

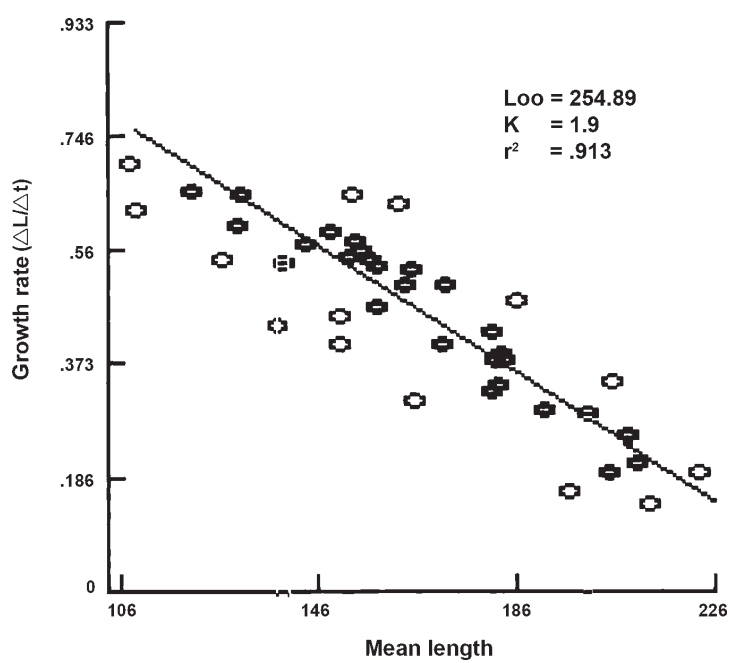

Fig. 2b. Growth curve obtained by Gulland and Holt plot in females

(October-December) that gave rise to summer cohort during March to May which contributed to the major fishery (Mane, 2007). Mean size of the cohort recruited to the nearshore and offshore fishing grounds during March-May ranged from $113.8 \mathrm{~mm}$ to $121 \mathrm{~mm}$ (Mane, 2007). Assuming peak spawning season as November and considering the larval period as one month (until they become benthic) the age of prawns in March-April would be 4-5 months. Considering the growth parameters estimated in the present investigation (Fig. 1), the size ranges of 4-5 month old male and female prawns were 104-120 $\mathrm{mm}$ and 121-139 $\mathrm{mm}$ respectively, which substantiate well with the observed size during sampling.

The earlier studies on the age and growth of $P$. merguiensis by Lucas et al. (1979) showed asymptotic carapace length as $38 \mathrm{~mm}$ and growth coefficient as 0.08 on weekly basis $(0.35 /$ month). On conversion of carapace length to total length by using Carapace length - Total length relation by Mane (2007), the asymptotic total length in Australian waters (TL - $167 \mathrm{~mm}$ ) appears to be far smaller than the maximum size observed in the present study (female with TL - $238 \mathrm{~mm}$ ). With the parameters reported by Lucas et al. (1979) the species grows to $103 \mathrm{~mm}$ and $142.5 \mathrm{~mm}$ in 12 and 24 weeks respectively. The present study showed the size attained by the females was more comparable with total length of $89 \mathrm{~mm}$ and $147 \mathrm{~mm}$ in the same time span respectively. Further, Lucas et al. (1979) did not consider differential growth exhibited by the sexes. It is well established that the females of penaeid prawns grow larger in size and more rapidly than males (Garcia and Le Reste, 1981).

In culture experiments carried out in Australia, Kirkegaard et al. (1975) reported that male and female $P$. merguiensis grew from $65 \mathrm{~mm}$ to $129 \mathrm{~mm}$ and $67 \mathrm{~mm}$ to $136 \mathrm{~mm}$ respectively within 4 months. This time interval appears to be rather longer when compared to the growth rate noticed in the present study. With the estimated growth parameters, the males and females would attain the same lengths in 3.5 and 2.9 months respectively. The longer growth time interval noted by Kirkegaard et al. (1975) could be due to lower temperatures in the pond conditions. Later on, Haywood and Staples (1993) reported that the growth of juvenile banana prawn in the estuarine

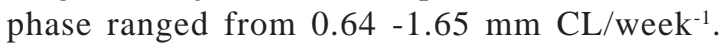
Conversion of carapace length to total length reveals that the juveniles attain $146 \mathrm{~mm}$ in 20 weeks, which appears to be in agreement with $130.4 \mathrm{~mm}$ attained 
by the females in the present studies. Sumiono (1988) reported growth parameters of the species as $\mathrm{L}_{\infty}=$ 200 and $214 \mathrm{~mm}$ and $\mathrm{K}$ as 1.31 and 1.05 for males and females respectively. The sizes attained in six months and one year are $96 \mathrm{~mm}$ and $146 \mathrm{~mm}$ for males and 86.7 and $138.4 \mathrm{~mm}$ for females which also indicates that females grow slower than males; therefore, the parameters reported appear to be invalid.

Hoang et al. (2002) reared the species in Queensland, Australia and observed growth of the species in ponds with different temperature and culture conditions. Female prawns attained $138 \mathrm{~mm}$ in 7.3 months in covered ponds (with temperature range of $20.0-28.5^{\circ} \mathrm{C}$ ) and $132 \mathrm{~mm}$ in 8.7 months in indoor tanks (temperature range of 26.7 - 27.2C) while in outdoor tanks (temperature range of 14.2 23.1C) where the temperature fluctuations were more, the females attained only $124 \mathrm{~mm}$ in 9.6 months. These experiments clearly indicate that growth of $P$. merguiensis largely depends on the ambient water temperature. The growth of the species observed by Hoang et al. (2002) in the covered ponds is comparable with that observed in the present study, where the seawater temperature (off Mumbai) is $27^{\circ}-28^{\circ} \mathrm{C}$ (Bapat et al., 1982). Assuming the age of post-larvae (PL 21) approximately 4 weeks and subtracting it from 7.3 months culture period, the age of $138 \mathrm{~mm}$ size prawns in the covered pond is about 6.3 months, which agrees well with the present findings of 6.3 months old males (Fig. 1).

In Indian waters, Achuthankutty and Parulekar (1986) estimated growth parameters as $\mathrm{L}_{\infty}=184.1$ $\mathrm{mm}$ and $242.8 \mathrm{~mm}$ and $\mathrm{K}=1.18$ and 0.6 per year for males and females of $P$. merguiensis respectively. The asymptotic lengths appear to be in accordance with the present study, but the growth coefficients are lower when compared with the present investigation. Within the sexes also the growth coefficients widely vary, as a result the male and female prawns would attain $127.5 \mathrm{~mm}$ and $109.5 \mathrm{~mm}$ in one year which violates the basic concept that females grow faster than males in penaeid prawns (Garcia and Le Reste, 1981). Bhadra and Biradar (2000) estimated $\mathrm{L}_{\infty}$ of the species as $220 \mathrm{~mm}$ and
$280.76 \mathrm{~mm}$ and $\mathrm{K}$ as 1.8 and 1.75 for males and females respectively; however, maximum sizes reported by them were $229 \mathrm{~mm}$ for males and 309 $\mathrm{mm}$ for females from Mumbai waters, which appear unconvincing.

Lalitha Devi (1986) and Rao et al. (1993) studied related species $P$. indicus from east coast of India. The former gave growth coefficient as 2.0 and 1.8 and the asymptotic lengths as 218.9 and $230 \mathrm{~mm}$ for males and females respectively, while the latter reported $\mathrm{K}$ value as 2.0 for both the sexes and asymptotic lengths as $200 \mathrm{~mm}$ and $230 \mathrm{~mm}$ for males and females respectively. The growth coefficients given by them are comparable to the present estimates. From Pakistan waters Sultana (2000) gave bionomics and growth of a closely related species $P$. penicillatus and stated that females reach $175 \mathrm{~mm}$ length in 6 months, which however, appears to be faster than the size attained by $P$. merguiensis in the same period from Maharashtra waters.

From the present studies it can be inferred that $P$. merguiensis grows faster than $P$. indicus but slower than $P$. penicillatus along the west coast of Indian subcontinent and males of the species attain 180.7 $\mathrm{mm}$ and females $216.8 \mathrm{~mm}$ in one year.

\section{Acknowledgements}

The authors are grateful to AP-Cess fund for the financial support and the Director, CMFRI for the facilities. We also acknowledge the help rendered by Dr. Sujit Sundaram, Dr. Abhay Hule and Mr. Milind Sawant.

\section{References}

Achuthankutty, C. T. and A. H. Parulekar. 1986. Growth of penaeid prawns in Goa waters. Indian J. Mar. Sci., (15): 117-120.

Appeldoorn, R. 1987. Modification of seasonal oscillating function for use with mark-recapture data. J. Cons. CIEM, 43: 194-198.

Agasen, E. V. and C. M. D. Mundo. 1988. Growth and mortality and exploitation rates of Penaeus indicus in Manila Bay, Philippines and southeast India. In: S. C. Venema, J. M. Christensen and D. Pauly (Eds.) Contribution to Tropical Fisheries Biology. FAO Fish. Rep., (389): 519 pp. 
Banerji, S. K. and M. J. George. 1967. Size distribution and growth of Metapenaeus dobsoni (Miers) and their effects on the trawler catches off Kerala. Proc. Symp. Crustacea. Mar. Biol. Ass. India., part II: 634-648.

Bapat, S. V., V. M. Deshmukh, B. Krishnamurty, C. Muthia, P. V. Kagwade, C. P. Ramamirtham, K. J. Mathew, S. Krishnapillai and C. Mukundan. 1982. Fishery resources of the exclusive economic zone of the northwest coast of India. Bull. Cent. Mar. Fish. Res. Inst., 33: 86 pp.

Bhadra, S. and R. S. Biradar. 2000. Population dynamics of penaeid prawn Penaeus merguiensis off Mumbai coast. J. Indian Fish. Ass., 27: 65-77.

Deshmukh, V. D. 2007. Reproductive dynamics of penaeid prawns in Maharashtra. Report submitted to AP Cess Fund ICAR, New Delhi, 113 pp.

Devaraj, M. 1983. Fish population dynamics. A course manual. CIFE Bull., 3(10) 83: 98 pp.

Faben, A. J. 1965. Properties and fitting of the von Bertalanffy growth curve. Growth, 29: 265-289.

Garcia, S. and L. Le Reste. 1981. Life cycles, dynamics, exploitation and management of coastal penaeid shrimp stocks. FAO Fish. Tech. Pap., 203: 215 pp.

Gayanilo, F. C., P. Sparre and D. Pauly. 1996. The FAOICLARM Stock Assessment Tools (FiSAT). User's guide. FAO computerized Information Series (Fisheries) No 8, Rome FAO, 124 pp.

Gulland, J. A. and S. J. Holt. 1959. Estimation of growth parameters for data at unequal time intervals. J. Cons. CIEM, 25(1): 47-49.

Hoang, T., S. Y. Lee, C. P. Keenan and G. E. Marseden. 2002. Observation on growth, sexual maturity and spawning performance of pond-reared Penaeus merguiensis. Aquac. Res., 33: 863-873.

Haywood, M. D. E. and D. J. Staples. 1993. Field estimates of growth and mortality of juvenile banana prawn (Penaeus merguiensis). Mar. Biol., 116: 3.

Kirkegaard, I., D. J. Tuma and R. H. Walker. 1975. Synopsis of biological data on the banana prawn $P$. merguiensis CSIRO, Fisheries and Oceanography division. Fisheries synopsis, 8 .
Kurata, H. 1962. Studies on the age and growth of crustacea. Bull. Hokkaido reg. Fish. Res. Lab., 24: 1-115.

Lalitha Devi, S. 1986. Growth and population dynamics of the Indian white prawn Penaeus indicus H M Edwards from Kakinada. Proc. Indian Acad. Sci. (Anim. Sci), 95(5): 629-639.

Lucas, C., G. Krikwood and I. Somers. 1979. An assessment of the stock of the banana prawn P. merguiensis in the Gulf of Carpentaria. Aust. J. Mar. Freshwater Res., 30: 639-652.

Mane, S. J. 2007. Investigation on the biological management of Penaeus merguiensis De Man in costal waters off Maharashtra, Ph.D. Thesis, University of Mumbai, India, 208 pp.

Pauly, D. and J. F. Caddy. 1985. Modification of Bhattacharya's method for the analysis of mixtures of normal distributions. FAO Fish. Circ., 781: 16 pp.

Pauly, D. and N. David. 1981. A basic programme for the objective extraction of growth parameter from length frequency data. Meeresforsch. Rep. Mar. Res., 28(4): 205-211.

Rao, G. S., V. T. Subramaniam, M. Rajamani, P. E. S. Manickam and G. Maheshwarudu. 1993. Stock assessment of Penaeus sp. off the east coast of India. Indian. J. Fish., 40(1\&2): 1-19.

Raje, P. C. and M. R. Ranade. 1972. Larval development of Indian penaeid shrimp- Penaeus merguiensis De Man. J. Indian Fish. Assoc., 2(1\&2): 1-16.

Sultana, R. 2000. Bionomics and population structure of juvenile shrimp with special reference to the genus Penaeus occurring in Karachi backwaters. Ph.D. Thesis. University of Karachi.

Sumiono, B. 1988. Estimation of growth and mortality in banana prawn (Penaeus merguiensis) from the south coast of Java, Indonesia. In: S. C. Venema, J. M. Christensen and D. Pauly (Eds.) Contribution to Tropical Fisheries Biology. FAO Fish. Rep., 389: 519 pp.

Wetherall, J. A., J. J. Polovina and S. Ralston. 1987. Estimating growth and mortality in steady-state fish stocks from length-frequency data. ICLARM Conf. Proc., (13): 53-74.
Received : 25/09/2009

Accepted : 16/09/2011

Published : 15/12/2011 